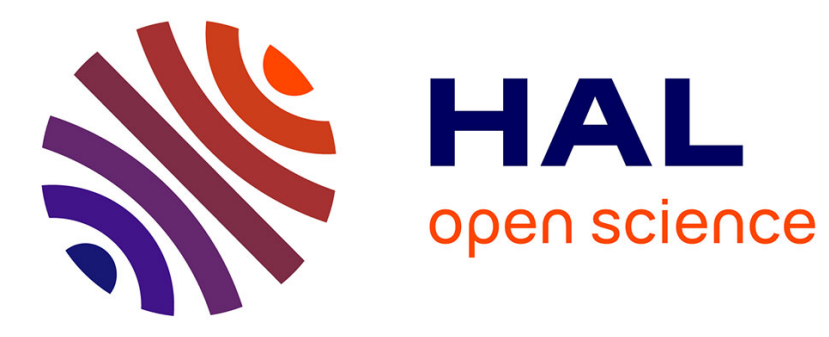

\title{
Optimization of the control of a doubly fed induction machine
}

Jules Gillet, Maria Pietrzak David, Frédéric Messine

\section{To cite this version:}

Jules Gillet, Maria Pietrzak David, Frédéric Messine. Optimization of the control of a doubly fed induction machine. 11th International Workshop of Electronics, Control, Measurement, Signals and their application to Mechatronics (ECMSM 2013), Jun 2013, Toulouse, France. pp.1-5, 10.1109/ECMSM.2013.6648968 . hal-01178572

\section{HAL Id: hal-01178572 \\ https://hal.science/hal-01178572}

Submitted on $20 \mathrm{Jul} 2015$

HAL is a multi-disciplinary open access archive for the deposit and dissemination of scientific research documents, whether they are published or not. The documents may come from teaching and research institutions in France or abroad, or from public or private research centers.
L'archive ouverte pluridisciplinaire HAL, est destinée au dépôt et à la diffusion de documents scientifiques de niveau recherche, publiés ou non, émanant des établissements d'enseignement et de recherche français ou étrangers, des laboratoires publics ou privés. 


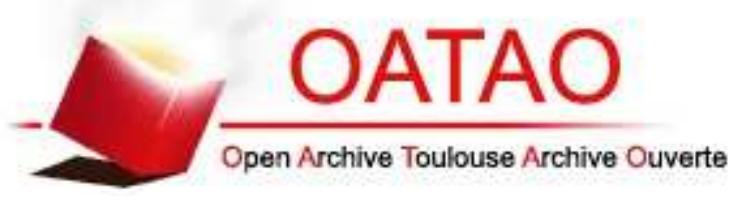

\section{Open Archive TOULOUSE Archive Ouverte (OATAO)}

OATAO is an open access repository that collects the work of Toulouse researchers and makes it freely available over the web where possible.

This is an author-deposited version published in : http://oatao.univ-toulouse.fr/ Eprints ID : 13013

URL: http://dx.doi.org/10.1109/ECMSM.2013.6648968

To cite this version : Gillet, Jules and Pietrzak-David, Maria and Messine, Frédéric Optimization of the control of a doubly fed induction machine. (2013) In: 11th International Workshop of Electronics, Control, Measurement, Signals and their application to Mechatronics (ECMSM), 24 June 2013 - 26 June 2013 (Toulouse, France).

Any correspondance concerning this service should be sent to the repository administrator: staff-oatao@listes-diff.inp-toulouse.fr 


\title{
Optimization of the control of a doubly fed induction machine
}

\author{
Jules Gillet ${ }^{1}$, Maria Pietrzak - David ${ }^{1}$, Frédéric Messine ${ }^{2}$ \\ ${ }^{1}$ Université de Toulouse; INPT; UPS; LAPLACE. \\ ${ }^{2}$ Université de Toulouse; INPT; UPS; IRIT. \\ ${ }^{1,2}$ ENSEEIHT, 2 rue C. Camichel, BP 7122 \\ ${ }^{1,2}$ F31071Toulouse Cedex 7, France. \\ Toulouse, France. \\ (jules.gillet) (maria.david)@laplace.univ-tlse.fr; frederic.messine@n7.fr
}

\begin{abstract}
This paper focuses on finding an optimal control for a doubly fed induction machine (DFIM) in motor mode. Our purpose is not to improve the quality of the DFIM functioning but to find a method to improve it. Thus we will start with a fixed system made by a DFIM and two ideal 3 phases voltage inverter with an open loop static V/f control. A method will demonstrate its efficiency to improve that control for the copper loss.
\end{abstract}

This method is based on direct shooting techniques associated with a MATLAB optimization solver: fmincon.

Keywords-Doubly fed induction machine (DFIM); ideal 3 phases voltage inverter; open loop static V/f control; copper loss; direct shooting method; optimization; energetic efficiency

\section{INTRODUCTION}

The Doubly Fed Induction Machine (DIFM) is often used as a Doubly Fed Induction Generator (DFIG). That is why, works are done to optimize the DFIG functioning as in [1] and [2]. Control of DFIM has been developed in [3], but now the goal is to find a method to optimize it, for example versus the copper loss.

In this paper, a presentation of the studied system, (a DFIM in motor mode fed by two ideal voltage inverters with an open loop static V/f control), will be made. A very simple DFIM open loop control is chosen to point the optimization aspect to reduce the cooper loss. Thus, a model of this system will be given. With this model, the direct shooting method will be developed and used. Finally the results will be simulated to compare them with a traditional ramp control.

The system is presented in Section II and its model is described in Section III. The optimization problem and methods are shown in Section IV. And finally, in section V the numerical results so obtained are validated with SABER ( software.

\section{SYSTEM PRESENTATION}

The system is composed as in Fig. 1:

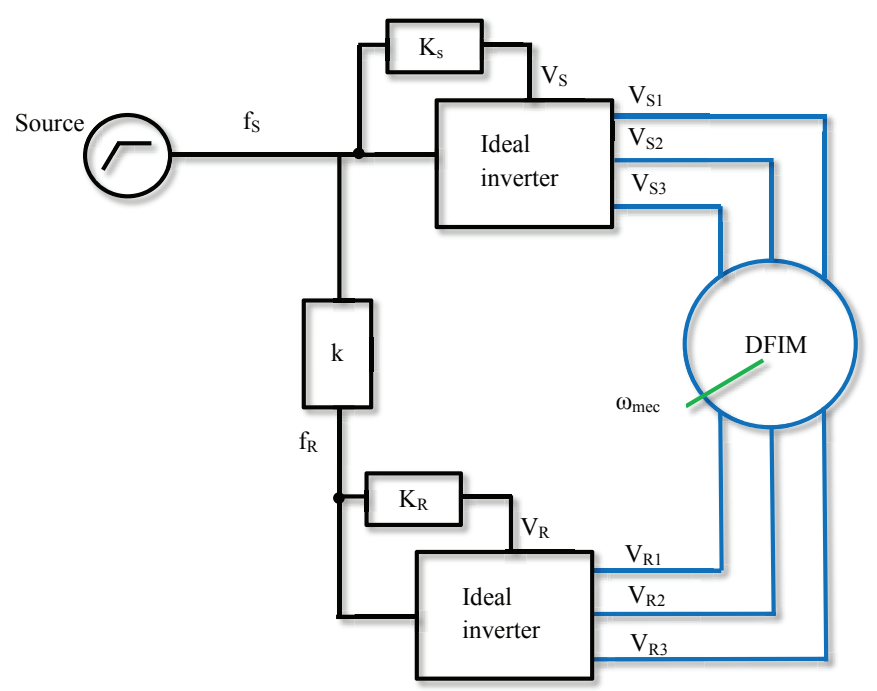

Fig. 1. General schema of DFIM drive controled by static V/f.

$\mathrm{K}_{\mathrm{S}}=$ static $\mathrm{V} / \mathrm{f}$ constant for the stator side,

$\mathrm{K}_{\mathrm{R}}=$ static $\mathrm{V} / \mathrm{f}$ constant for the rotor side.

The source gives a continuous signal $f_{s}(t)$ which is the control of this DFIM. With this signal, $f_{r}(t)$ is calculated. Those signals represent the electrical variable frequencies of the stator and the rotor respectively. The corresponding value of the supply tension of the DFIM is calculated with them. For those transformations, ideal 3 phases voltage inverters are used. They have as inputs, a frequency and an amplitude and give an equilibrated tension system at the end to feed the DFIM.

The aim is to try to optimize the stator frequency signal $f_{s}(t)$. 


\section{MODELING}

In this part, the model used in the optimization method is described. The static converter model is not used at the beginning because the goal is to reduce the copper loss in the motor. It makes a simplified model, to focus on the DFIM, as it is the real purpose.

\section{A. DFIM Model}

The DFIM model used in this paper is developed in François Bonnet's PhD thesis [4].

The expression of the control $u(t)$ is put in the expressions of frequencies:

$f_{s}(t)=k \times u(t) \times t \quad$ and $\quad f_{R}(t)=u(t) \times t$,

with:

$f_{s}(t)$ - electrical values frequencies of the stator,

$f_{r}(t)$ - electrical values frequencies of the rotor,

$u(t)$ - system control variable,

$k$ - frequency repartition coefficient between rotor and stator.

This formulation is used to avoid frequency step.

Now, according to the used control (static V/f law) the effective (rms) values of tensions are:

$$
\begin{aligned}
& V_{S}(t)=f_{S}(t) \times 2 \pi \times \Phi_{S N} \\
& \text { and } V_{R}(t)=f_{R}(t) \times 2 \pi \times \Phi_{R N}
\end{aligned}
$$

with:

$\Phi_{S N}$ - nominal stator flux,

$\Phi_{R N}$ - nominal rotor flux,

$V_{S}(t)$ - effective value of the stator tension,

$V_{R}(t)$ - effective value of the rotor tension.

These equations are transformed to a static frame (Concordia basis) [5] to express the tension system with the flux:

$$
\left[\begin{array}{c}
V_{S \alpha} \\
V_{S \beta} \\
V_{R \alpha} \\
V_{R \beta}
\end{array}\right]=\mathbf{R}_{\text {mat }} \mathbf{L}_{\text {mat }}{ }^{-1}\left[\begin{array}{c}
\Phi_{S \alpha} \\
\Phi_{S \beta} \\
\Phi_{R \alpha} \\
\Phi_{R \beta}
\end{array}\right]+\frac{d}{d t}\left[\begin{array}{c}
\Phi_{S \alpha} \\
\Phi_{S \beta} \\
\Phi_{R \alpha} \\
\Phi_{R \beta}
\end{array}\right],
$$

with:

$$
\mathbf{R}_{\text {mat }}=\left[\begin{array}{cc}
\mathbf{R}_{\mathbf{S S}} & 0 \\
0 & \mathbf{R}_{\mathbf{R R}}
\end{array}\right],
$$

$$
\begin{aligned}
\mathbf{R}_{\mathbf{S S}} & =\left[\begin{array}{cc}
R_{S} & 0 \\
0 & R_{S}
\end{array}\right], \mathbf{R}_{R R}=\left[\begin{array}{cc}
R_{R} & 0 \\
0 & R_{R}
\end{array}\right] \\
\mathbf{L}_{\text {mat }} & =\left[\begin{array}{cccc}
L_{S} & 0 & M \cos \theta & -M \sin \theta \\
0 & L_{S} & M \sin \theta & M \cos \theta \\
M \cos \theta & M \sin \theta & L_{R} & 0 \\
-M \sin \theta & M \cos \theta & 0 & L_{R}
\end{array}\right] .
\end{aligned}
$$

And finally, the expression of the currents with the flux is:

$$
\left[\begin{array}{c}
I_{S \alpha} \\
I_{S \beta} \\
I_{R \alpha} \\
I_{R \beta}
\end{array}\right]=\mathbf{L}_{\text {mat }}{ }^{-1}\left[\begin{array}{c}
\Phi_{S \alpha} \\
\Phi_{S \beta} \\
\Phi_{R \alpha} \\
\Phi_{R \beta}
\end{array}\right],
$$

with:

$L_{S} L_{R}$ - cyclic stator, rotor inductance,

$M$ the cyclic mutual inductance between the stator and the rotor,

$R_{S} R_{R}$ - stator rotor resistance,

$I_{S \alpha} I_{S \beta}$ - stator currents in the $\alpha, \beta$ axes,

$I_{R \alpha} I_{R \beta}$ - rotor currents in the $\alpha, \beta$ axes,

$V_{S \alpha} V_{S \beta}$ - stator voltage in the $\alpha, \beta$ axes,

$V_{R \alpha} V_{R \beta}$ - rotor voltage in the $\alpha, \beta$ axes,

$\phi_{S \alpha} \phi_{S \beta}$ - stator flux in the axis $\alpha, \beta$ axes,

$\phi_{R \alpha} \phi_{R \beta}$ - rotor flux in the axis $\alpha, \beta$ axes.

Rotor electrical position and speed can be defined as follows: $\theta=\frac{d \omega}{d t}$ and $\omega=2 \pi\left(f_{S}(t)-f_{R}(t)\right)$.

\section{B. Toward an optimization formulation}

The model equations are put in a suitable form for optimization. A state representation is given by:

$$
\dot{\mathbf{X}}=\mathbf{A X}+\mathbf{B}(u)
$$

where:

Sate vector matrix: $\mathbf{X}=\left[\begin{array}{c}I_{S \alpha} \\ I_{S \beta} \\ I_{R \alpha} \\ I_{R \beta}\end{array}\right]$.

Dynamic system matrix: $\mathbf{A}=\mathbf{R}_{\text {mat }} \mathbf{L}_{\text {mat }}{ }^{-1}$. 
Control matrix: $\mathbf{B}(u)=\mathbf{L}_{\text {mat }}{ }^{-1}\left[\begin{array}{c}V_{S \alpha} \\ V_{S \beta} \\ V_{R \alpha} \\ V_{R \beta}\end{array}\right]$.

\section{OPTIMIZATION PROBLEM}

We introduce the mode separation principle. In this case, the temporal derivative of $\theta$ is considered as null because the electrical variables evolve faster than the mechanic ones.

The main point developed here is to find a solution to minimize the copper loss, so the cost function will be:

$E_{J}(u)=\int_{0}^{t_{f}} 3 R_{S}\left(I_{S \alpha}{ }^{2}+I_{S \beta}{ }^{2}\right)+3 R_{R}\left(I_{R \alpha}{ }^{2}+I_{R \beta}{ }^{2}\right) d t$

Following the state equation (7), with an time horizon $t_{f}=3$ seconds, the physical constraints are defined by:

$0<I_{S i}<I_{S n}$ Stator current limitation to nominal values,

$0<I_{R i}<I_{R n}$ Rotor current limitation to nominal values,

$0<V_{S i}<230 \mathrm{~V}$ Stator voltage limitation to nominal values,

$0<V_{R i}<130 \mathrm{~V}$ Rotor voltage limitation to nominal values,

$0<\omega=2 \pi\left(f_{S}-f_{R}\right)<188 \mathrm{rad} / \mathrm{s}$ Speed limitation.

At $\mathrm{t}=3 \mathrm{~s}$ the final rotation speed must be reached:

$\Omega=\Omega_{\text {final }}=188 \mathrm{rad} / \mathrm{s}$ Final speed.

\section{A. Indirect shooting method}

First Pontryagin Max Principle [6] was investigated but the Hamiltonian of the system is too complex to yield a differential system of equations which could be efficiently numerically solved.

To illustrate, here is the Hamiltonian:

$$
\begin{aligned}
& H=-\left(3 R_{S}\left(I_{S a}^{2}+I_{S \beta}^{2}\right)+3 R_{R}\left(I_{R a}^{2}+I_{R \beta}^{2}\right)\right) \\
& +\frac{1}{\mathcal{M} c^{2}-\mathcal{L}_{S} \mathcal{L}_{R}}\left(z _ { 1 } \left(-\mathcal{L}_{R} R_{S} I_{S a}+R_{R} \mathcal{M} I_{R a} \cos \theta-R_{R} \mathcal{M} I_{R \beta} \sin \theta\right.\right. \\
& -\mathcal{L}_{R} k \phi_{S n} 2 \pi \sqrt{3} u t \sin \left(k 2 \pi u t^{2}\right)+\mathcal{M} \cos \theta \phi_{R n} 2 \pi \sqrt{3} u t \sin \left(2 \pi u t^{2}\right) \\
& \left.-\mathcal{M} \sin \theta \phi_{R n} 2 \pi \sqrt{3} u t \cos \left(2 \pi u t^{2}\right)\right) \\
& +z_{2}\left(-\mathcal{L}_{R} R_{S} I_{S \beta}+R_{R} \mathcal{M} I_{R \theta} \cos \theta+R_{R} \mathcal{M} I_{R a} \sin \theta-\mathcal{L}_{R} k \phi_{S n} 2 \pi \sqrt{3} u t \cos \left(k 2 \pi u t^{2}\right)\right. \\
& \left.+\mathcal{M} \sin \theta \phi_{R n} 2 \pi \sqrt{3} u t \sin \left(2 \pi u t^{2}\right)+\mathcal{M} \cos \theta \phi_{R n} 2 \pi \sqrt{3} u t \cos \left(2 \pi u t^{2}\right)\right) \\
& +z_{3}\left(-\mathcal{L}_{S} R_{R} I_{R a}+R_{S} \mathcal{M} I_{S a} \cos \theta+R_{S} \mathcal{M} I_{S \beta} \sin \theta-\mathcal{L}_{S} \phi_{R n} 2 \pi \sqrt{3} u t \sin \left(2 \pi u t^{2}\right)\right. \\
& \left.+\mathcal{M} \cos \theta k \phi_{S n} 2 \pi \sqrt{3} u t \sin \left(k 2 \pi u t^{2}\right)+\mathcal{M} \sin \theta k \phi_{S n} 2 \pi \sqrt{3} u t \cos \left(k 2 \pi u t^{2}\right)\right) \\
& +z_{4}\left(-\mathcal{L}_{S} R_{R} I_{R \beta}+R_{S} \mathcal{M} I_{S \beta} \cos \theta-R_{S} \mathcal{M} I_{S a} \sin \theta-\mathcal{L}_{S} \phi_{R n} 2 \pi \sqrt{3} u t \cos \left(2 \pi u t^{2}\right)\right. \\
& \left.\left.-\mathcal{M} \sin \theta k \phi_{S n} 2 \pi \sqrt{3} u t \sin \left(k 2 \pi u t^{2}\right)+\mathcal{M} \cos \theta k \phi_{S n} 2 \pi \sqrt{3} u t \cos \left(k 2 \pi u t^{2}\right)\right)\right)
\end{aligned}
$$

Because of the complexity of the Hamiltonian the optimal control is difficult to find.

\section{B. Direct shooting method}

Secondly the direct shooting method [7] is used. This method is based on the discretion of the time by small steps $h$. Hence, this yields to solve a large scale static optimization problem:

$$
\min _{u^{i} \in \Re^{N}} \sum_{0}^{N} X^{i+1}=X^{i}+h\left(A X^{i}+B\left(u^{i}\right)\right)
$$

with the same constraints than previously.

For solving this large scale optimization problem the fmincon function of MATLAB is used to optimize a vector of $\mathrm{N}$ points representing the values of the control $u(t)$ at each step of the discretized time. As a result, a vector of $\mathrm{N}$ points is given by the routine and at the end it will correspond to the optimal control for the system.

As the final electrical frequency is about $26 \mathrm{~Hz}$ the time step must be small. That is why this is a large scale optimization problem. To begin a small amount of point is used with a small temporal horizon with always a small time step. Then after checking the results we enlarge the time horizon as well as the number of point to obtain the final optimization.

Numerical solutions are reported in Fig. 2, 3, 4 and 5 for $\mathrm{N}=500$. Those results must be checked by comparing them with a simulation tool.

\section{VALIDATION OF THE OPTIMAL SOLUTION}

In order to validate this optimization method SABER C software is used. The same schema than in presentation (Fig. 1) is used twice. One way to simulate the regular ramp control, and the other way to simulate the optimized control.

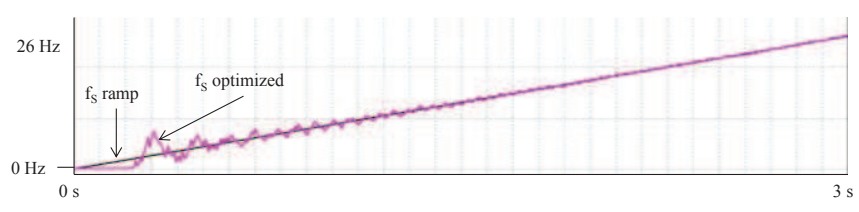

Fig. 2. Control sources for the systems.

The control is shown in the Fig. 2. In black, the regular control input and in pink the optimized control input. These signals are given as sources in the system.

The outputs of these control signals, i.e., the rotation speed, have the shape as showed in Fig. 3: 


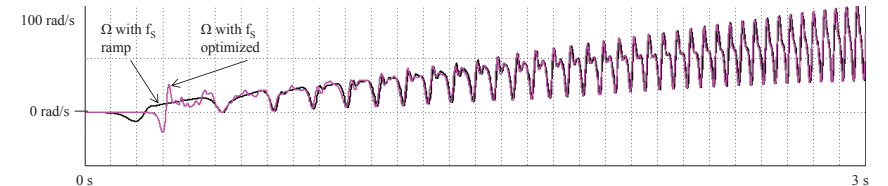

Fig. 3. Systems responses (rotation speed).

The response is shown in Fig. 3. In black, the response with the regular ramp control, and in pink the response with the optimized one. These signals are given as sources in the system.

As said at the beginning, the quality of the torque or the rotation speed is not the aim, what is important is that at the end, with the two different controls, the DFIM has the same behavior.

Now, the main result:

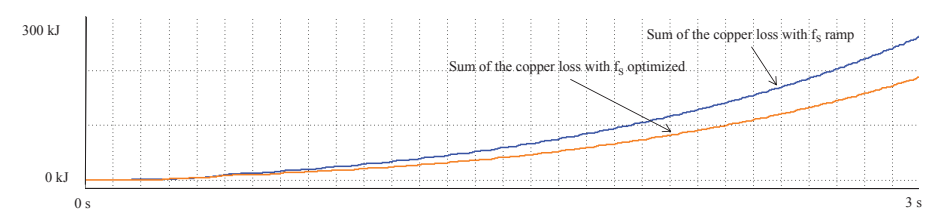

Fig. 4. Copper loss sum $\mathrm{E}_{\mathrm{J}}(7)$.

As shown in Fig. 4, the sum of the copper loss is lowered by $28 \%$ in the case of an optimized control.

Electrical quantities can also be shown:

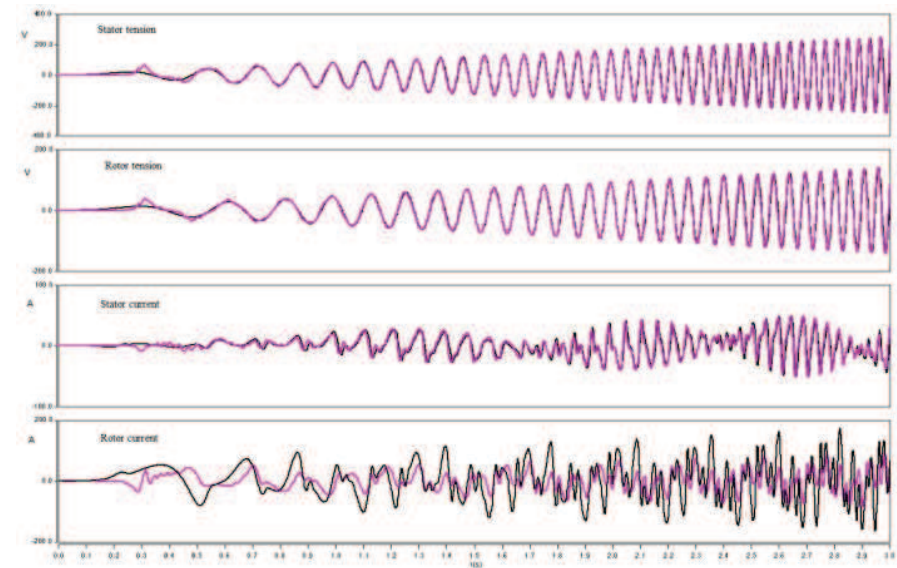

Fig. 5. In pink, the "optimized" electrical quantities and in black, the other one.

In Fig 5 the electrical quantities appears similar in both case except for the rotor current witch is lower in the optimized case.

\section{CONCLUSION}

In many industrial applications, the power system architecture is given. And one way to improve the system performances can be trough the control strategy.

In this paper, the authors present the direct shooting method to optimize efficiently the behavior of a DFIM speed drive. This optimization concept allows us to adapt the control strategy to the required operation of the system taking into account the formulated constraints.

The optimization process is very difficult in real time. Consequently, a very simple control method, V/f law, was chosen to validate the optimization method applied in deferred time.

To calculate this direct shooting method, we have to choose the control input, to place it in the system model and to define the cost function to be optimized. The main problem is the compromise between the time scale and the number of points to represent clearly and precisely the principle variables of the studied system.

In the next step of this study, the cost function can be completed with iron loss or torque quality for example, and the control can be switched to a more complex one such as the non linear Double Direct Torque Control (DDTC) or the linear Field Oriented Control (FOC). The model of two real voltage inverters (one for the stator side and one for the rotor side) can be added too. The cost function could be eventually completed with the losses of them.

In future works, the global optimization aspect will be considered to associate different real time controls to the DFIM system to improve their performances.

\section{REFERENCES}

[1] Heng Nian, Jiabing hu, Jia-wen li: "Multi-objective optimization control of DFIG system under distorted grid voltage conditions" IEEE Electrical Machines and Systems (ICEMS), 2011 International Conference on. http://ieeexplore.ieee.org/xpls/abs_all.jsp?arnumber=6073461

[2] P. Chakravarty: "Development of optimal controllers for a DFIG based wind farm in a smart grid under variable wind speed conditions" IEEE Electric Machines \& Drives Conference (IEMDC), 2011 IEEE International.

http://ieeexplore.ieee.org/xpls/abs_all.jsp?arnumber=5994901

[3] M. Abdellatif, M. Pietrzak-David, I. Slama-Belkhodja: "Sensitivity of the currents input-output decoupling vector control of the DFIM versus current sensors fault" IEEE Power Electronics and Motion Control Conference, 2008. EPE-PEMC 2008.

http://ieeexplore.info/stamp/stamp.jsp?tp=\&arnumber $=4635388$

[4] François Bonnet: «Contribution à l'Optimization de la Commande d'une Machine Asynchrone à Double Alimentation utilisée en mode Moteur » pp. 43-49, Ph-D Thesis, INP-Toulouse.

http://ethesis.inp-toulouse.fr/archive/00000679/01/bonnet.pdf

[5] François Bonnet: «Contribution à l'Optimization de la Commande d'une Machine Asynchrone à Double Alimentation utilisée en mode Moteur » Annexe D pp XXI-XXV, Ph-D Thesis, INP-Toulouse. http://ethesis.inp-toulouse.fr/archive/00000679/01/bonnet.pdf

[6] Emmanuel Trelat: "Contrôle optimal: Théorie et applications » ed Vuibert, Collection "Mathématiques Concrètes", pp. 103-112. 
http://www.ljll.math.upmc.fr/ trelat/fichiers/livreopt.pdf

[7] Emmanuel Trelat: "Contrôle optimal: Théorie et applications » ed Vuibert, Collection "Mathématiques Concrètes", pp.197-199. http://www.ljll.math.upmc.fr/ trelat/fichiers/livreopt.pdf 